\title{
As transferências condicionadas de renda na América Latina: lenitivos para a pobreza?
}

\author{
Gepherson Macêdo Espínola \\ Universidade Federal da Bahia, Faculdade de Educação, Salvador, \\ BA, Brasil (UFBA)
}

\author{
Clóvis Roberto Zimmermann \\ Universidade Federal da Bahia, Faculdade de Filosofia e Ciências
}

Humanas, Salvador, BA, Brasil (UFBA)

\begin{abstract}
As transferências condicionadas de renda na América Latina: lenitivos para a pobreza?
Resumo: Esse texto discute a implementação dos programas de transferências condicionadas de renda na América Latina como estratégia de enfrentamento da pobreza na região. Para tanto, contextualiza sinteticamente o desenvolvimento latino-americano ao longo do tempo, evidenciando através de dados estatísticos não só os elevados índices de pobreza, como também as condições educacionais e de saúde. Estes programas, via de regra, objetivam o alívio e a superação da pobreza, através do repasse monetário e do cumprimento de agendas de saúde e educação que, em tese, aumentariam o capital humano dos pobres e permitiria o ultraje da pobreza no longo prazo. Conclui-se que, apesar de salientes para as famílias, os programas de transferências condicionadas de renda na América Latina, por si sós, ainda não são capazes de enfrentar a pobreza estrutural que assinala a região, promovem o lenitivo para as más condições de vida, sem superá-las.
\end{abstract}

Palavras-chave: Pobreza. Programas de Transferências Condicionadas de Renda. América Latina.

\section{Conditional Income Transfers in Latin America: Palliatives for poverty?}

Abstract: This text discusses the implementation of conditional income transfer programs in Latin America as a strategy to confront poverty in the region. It synthetically contextualizes Latin American development over time, using statistical data to reveal not only the high levels of poverty, but also educational and health conditions. These programs, as a rule, seek to alleviate and overcome poverty through monetary disbursements and fulfillment of health and educational agendas that, in thesis, increase the human capital of the poor and allow overcoming poverty in the long term. It concludes that despite the benefits for the families, the conditional income transfer programs of Latin America, on their own, are still not capable of confronting the structural poverty that marks the region, and are promoting palliatives for the poor living conditions, without overcoming them.

Keywords: Poverty. Conditional Income Transfer Programs. Latin America.

Recebido em 15.06.2017. Aprovado em 05.09.2017. Revisado em 19.10.2017.

(C) O(s) Autor(es). 2018 Acesso Aberto Esta obra está licenciada sob os termos da Licença Creative Commons Atribuição-NãoComercial 4.0 Internacional (https://creativecommons.org/licenses/bync/4.0/deed.pt_BR), que permite copiar, distribuir e reproduzir em qualquer meio, bem como adaptar, transformar e criar a partir deste material, desde que para fins não comerciais, e que você forneça o devido crédito aos autores e a fonte, insira um link para a Licença Creative Commons e indique se mudanças foram feitas. 


\section{Introdução}

O estabelecimento de uma renda monetária para auxiliar famílias em situação de pobreza e miséria, associado ao cumprimento de condicionalidades, notadamente nas áreas de saúde e educação, revela a intenção de se reprimir as causas da pobreza e o intuito de impedir a reprodução e o agravamento das más condições de vida. Na última década, nos países latino-americanos, tais programas se converteram enquanto estratégias de enfrentamento da pobreza. Porém, ressoam discussões ligadas ao efeito, à eficácia e a saliência destes programas no longo prazo, conduzindo aos seguintes questionamentos: esses programas são um lenitivo, um meio de ajustamento ou uma possibilidade para o ultraje da pobreza?

Este trabalho inicialmente estabelece abreviadas considerações acerca da trajetória do desenvolvimento regional latino-americano e sua interface com o panorama socioeconômico. Reconhece que a América Latina apresenta níveis acentuados de pobreza e desigualdade, fator que dificultou e dificulta a consecução do famigerado desenvolvimento. Com a finalidade de caracterizar a pobreza na região latino-americana são utilizados os dados estatísticos elaborados pela Comissão Econômica para a América Latina e o Caribe (CEPAL).

Posteriormente aborda-se a gênese dos programas de transferências condicionadas de renda e a ideia de que eles são mecanismos capazes de darem resposta, positiva ou negativa, ao problema da pobreza. Vale ressaltar que a discussão proposta se baseia em uma análise generalizada dos programas de transferências monetárias implementados na região latino-americana. Para tanto o debate se guia a partir das contribuições de autores que avaliam os traços em comum de tal política social.

\section{Desenvolvimento e pobreza: o cenário latino-americano}

Quando se colocam em pauta os desafios para o desenvolvimento da América Latina frente às dificuldades sociais, econômicas e políticas que assinalam os países que compõem essa região, seja, por exemplo, pelos gargalos que obstruem o alcance de um crescimento econômico capaz de diminuir a alarmante concentração de renda com altos índices de pobreza, pelo deficiente desempenho educacional e/ou pela falta de cobertura total dos serviços de saúde, os relatos historiográficos permitem afirmar que há uma espécie de convergência analítica - em que pesem diferentes correntes teóricas e ideológicas.

Há tempos em que se observam e se aplicam múltiplas teorias explicativas sobre déficits sociais dos/nos países da América Latina e propostas, medidas de superação dos mesmos. Muitas tentativas foram feitas, diferentes políticas econômicas e variadas políticas sociais sob distintas orientações e influências foram colocados em prática com o intuito de dar robustez ao continente e melhorar os índices socioeconômicos e a qualidade de vida da sua população. Registra-se a busca incessante pelo equilíbrio macroeconômico, pelo fortalecimento regional, pela minoração dos problemas sociais - e, até mesmo, tentativas de equacioná-los.

A partir da análise do cenário socioeconômico é possível asseverar que a América Latina, ao longo do tempo, conseguiu superar a posição de região aquém da economia global, inserindo-se na dinâmica econômica mundial, conforme afirmam Nascimento e Reis $(2009$, p. 184): "Esse avanço é permeado por marchas e contramarchas, que podem ser explicadas ora pelas fragilidades internas, ora pelas vulnerabilidades políticas e econômicas da região, frente a uma concorrência mundial cada vez mais acirrada".

A participação ascendente da região no circuito econômico mundializado é comumente explicada pela passagem do modelo econômico agrário-exportador para o industrializante. $\mathrm{O}$ efeito da bifurcação entre o agronegócio e a chamada agricultura familiar dá a ideia de abandono da tão propagada e reproduzida vocação agrícola desses países como atividade econômica hegemônica e central - que, diga-se de passagem, fora muito útil e conveniente para a circulação e escoamento de mercadorias para o mercado europeu no esquema de exportação de matérias-primas e importação de manufaturados e industrializados - teria aumentado a competitividade na arena global.

Nessa perspectiva e com o passar do tempo, a mão-de-obra latino-americana foi se deslocando e desconcentrando das atividades ligadas à exploração dos recursos da natureza (setor primário) para se intensificar no setor de serviços (terciário). Isso ratifica a mudança de paradigma da atividade econômica e do próprio mercado de trabalho dos países dessa região, em consonância com as mudanças nos processos de produção que incitam o desenvolvimento do mercado de serviços com vistas à potencialização das transações comerciais. Tal informação pode ser evidenciada pelos dados apurados pela CEPAL (2016) que demonstram a concentração da atividade econômica majoritariamente no setor de serviços, seguido da indústria e da agricultura, respectivamente - exceção apenas para Honduras e Peru que têm a agricultura como o segundo setor mais dinâmico, representando $36,2 \%$ e $31,1 \%$ da economia. 
Chama a atenção a tese da deterioração dos termos de troca desenvolvida pelos economistas cepalinos Prebisch e Singer com a finalidade de explicar os problemas oriundos do subdesenvolvimento da região em face da industrialização tardia. Em conformidade com essa teoria a condição de dependência dos países latinos era reproduzida e renovada com o intercâmbio comercial, dada a baixa valorização dos seus produtos no mercado internacional, reflexo da pouca capacidade competitiva que tais países possuíam diante dos seus concorrentes (COUTO, 2007). A dependência também era acompanhada de subordinação aos interesses dos países mais abastados que gozavam de economias mais estruturadas, maculando, desse modo, os projetos de desenvolvimento regional e aprofundando a relação de subalternidade da periferia em relação ao centro.

Sob outro prisma analítico, Chesnais (1998) compreende a integração, seja entre países ou regiões, como um mecanismo de propagação do ideário neoliberal cuja orientação é sucumbir todo e qualquer protecionismo com vistas à proliferação da mundialização financeira. Alinham-se a esse perspectivismo os argumentos apresentados por Costa Lima (2009) que mostram e ratificam a dependência dos países da América Latina aos interesses do capital internacional e de suas intempéries, além de elucidar que as raias territoriais são maleáveis e convenientes àqueles que detêm o poder econômico.

Os países latino-americanos ao se industrializarem procuraram diversificar os seus portfólios produtivos com vistas à expansão do produto, às possibilidades de comercialização e ao ganho de divisas. Muitos alimentaram a crença e a esperança de que a industrialização era condição sine qua non para o alcance do crescimento e desenvolvimento econômico e, consequentemente, superação dos problemas sociais da região - fato que não foi apurado empiricamente.

É pertinente ressaltar que a industrialização na região não foi feita de modo invariável e uniforme, tampouco concomitante, sendo registrado, em muitos países, o agravamento das condições de pobreza e desigualdade, dada a insuficiente criação de empregos, ao processo de reestruturação do mercado de trabalho, a falta de mão-de-obra qualificada para assumir os novos postos e atender as novas demandas laborais, o êxodo rural e o consequente inchaço urbano, o declínio dos salários e do seu poder de compra e a falta de estruturação das cidades para a expansão da oferta de serviços, relegando muitas famílias e indivíduos a própria sorte.

Somam-se a isso os obstáculos internos e específicos - que entravam o crescimento sustentado - e a dependência histórica da região em relação às nações que detêm o poder econômico e consequentemente político. Em que pesem as controvérsias, isso tem sido reforçado pela Teoria da Dependência desenvolvida pelos intelectuais cepalinos para elucidar sobre as estratégias do desenvolvimento capitalista enquanto mecanismo reprodutor das desigualdades, uma vez que o bom desempenho dos países centrais implicava na reprodução das disparidades e encurralamento das economias periféricas (BRESSER-PEREIRA, 2010).

A partir dessa linha de raciocínio compreende-se que os países latino-americanos por estarem, em linhas gerais, integrados à dinâmica econômica global em uma relação de subalternidade, em virtude de suas fragilidades econômicas, políticas e sociais, ficam reféns não só dos interesses das grandes economias, mas também das suas oscilações e crises.

As transformações na conjuntura mundial após a crise dos anos 1970, que refletia o desgaste da doutrina keynesiana e consequentemente a refutação do Estado interventor, reordenou e redefiniu a dinâmica entre Estado, mercado e sociedade, alterando, por sua vez, a ordem política, econômica e social. Segundo Balanco e Pinto (2008) naquele momento emergia a necessidade de retomada dos níveis de acumulação anteriormente registrados e acreditava-se que isso só seria possível através da coesão social, da reestruturação produtiva e da interação e integração dos mercados na rede mundial. Notou-se, então, o incentivo à liberalização e à promulgação da soberania do mercado que passou a balizar não só as relações econômicas, como também as sociais.

Para Mattei (2010) o momento vivenciado pela América Latina na década de 1980 de crise da dívida externa, aceleração inflacionária e estabilização econômica ortodoxa desencadeou a redução dos gastos públicos e estrangulou os programas sociais até então em curso. Em análise semelhante, Iglesias (2010, p. 45) atribui o pacote de medidas postas em prática na região como o retorno da ortodoxia que valorizou, ao máximo, o jogo de mercado e patrocinou a entrada de recursos financeiros e investimentos privados estrangeiros, além de uma política generalizada de privatizações, como guias das reformas.

Nesse sentido, as reformas então adotadas apoiavam-se nos parâmetros do Consenso de Washington e procuravam introduzir o triunfo do Estado neoliberal. Assim, reproduziam a ideia de ineficiência estatal, seja devido aos entraves burocráticos, ao clientelismo ou à corrupção. Entretanto, ainda de acordo com Iglesias (2010), as reformas falharam ao espezinharem o Estado, ao perderem a credibilidade dos cidadãos em virtude da desproporção entre o sacrifício feito e o progresso auferido e ao desconsiderarem o planejamento de longo prazo.

Avaliando o mesmo contexto, Nascimento e Reis (2009) defendem que a conjuntura incitou a formulação de medidas específicas para a resolução e/ou superação dos problemas sociais que se alastravam e perduravam na região latino-americana e, por isso e para tanto, registraram-se contribuições de países centrais e de organismos multilaterais - mesmo sob a regência da lógica neoliberal. 
A presença de organismos internacionais, tais como o Fundo Monetário Internacional e o Banco Mundial, como estimuladores de políticas públicas, notadamente as sociais, é percebida não só como um meio de incentivar o desenvolvimento e a superação das dificuldades dos países periféricos, mas também como um meio de reparar os danos causados pelo livre jogo de mercado que corroeu e fragilizou, ainda mais, a situação socioeconômica regional, dados os escassos investimentos.

Mendonça (2003), ao avaliar a realidade brasileira, advoga que o verdadeiro propósito das políticas públicas recomendadas pelas agências multilaterais, a partir da década de 1990, era incluir o país na ciranda econômica internacional - análise que pode ser estendida aos demais países latino-americanos, respeitadas as particularidades, sem incorreção no erro das generalizações. Ademais tem de se reconhecer que há uma vasta discussão repleta de polêmicas sobre as intenções, objetivos, finalidades e funções das políticas públicas no atual estágio de desenvolvimento capitalista, sem desconsiderar, contudo, a relevância das mesmas.

É lícito assinalar, nesse contexto, que foi do debate sobre a necessidade de se desenhar medidas capazes de proteger socialmente aqueles à margem do progresso que a temática pobreza ganhou destaque e passou a ser vista como um problema a ser equacionado e até mesmo desnaturalizado. As precárias condições de vida de milhares de famílias e indivíduos passaram a ser pauta de discussão e alvo de interesses das já citadas agências multilaterais e dos países centrais que passaram a incitar a formulação de políticas públicas de combate à pobreza e à desigualdade, notadamente nos países periféricos latino-americanos.

Reconheceu-se também que havia uma incoerência no debate sobre o tão almejado desenvolvimento por este não conferir a devida importância aos altos níveis de pobreza e desigualdades, que não apenas obstruíam como também ameaçavam a sustentabilidade das melhorias alcançadas pelo modo de produção capitalista. Assentam-se sob essa lógica os Objetivos de Desenvolvimento do Milênio promulgados e firmados pelos países membros da Organização das Nações Unidas no ano 2000 que ressoou na região, com destaque especial para o combate à fome e à miséria.

A ênfase da temática pobreza nas sociedades contemporâneas instigou a elaboração de distintos estudos e pesquisas que intencionaram aprimorar a sua compreensão para subsidiar o desenho de instrumentos de enfrentamento e prevenção mais eficazes. Observou-se a evolução do seu conceito que se deslocou da explicação exclusivamente monetarista - pobreza como ausência ou insuficiência de renda para a satisfação das necessidades sociais básicas ligadas à subsistência - para contemplar variáveis não monetárias também relevantes para assegurar a manutenção e reprodução da vida como educação, saúde, cultura, segurança, nutrição, habitação, assistência social etc.

A concepção adotada é de que a pobreza apresenta dimensões histórica, econômica, social, cultural e política; é complexa e multidimensional; é essencialmente de natureza estrutural, sendo, portanto, mais que insuficiência de renda. É produto da exploração do trabalho; é desigualdade na distribuição da riqueza socialmente produzida; é não acesso a serviços sociais básicos, à informação, ao trabalho e à renda digna; é não participação social e política. (SILVA, 2007, p. 1430).

Apesar de vários autores como, por exemplo, Rocha (2005), Sen (2005), Kageyama e Hoffmann (2006), Barros, Carvalho e Franco (2006), Silva (2007) e Espínola e Zimmermann (2012) reconhecerem, em suas pesquisas, a transversalidade da pobreza, a dificuldade de mensuração dos aspectos qualitativos e não materiais entravam o seu tratamento enquanto fenômeno múltiplo, condicionando a maioria das análises ao fator renda. Nesse sentido a identificação da população acometida pela pobreza é comumente feita através do estabelecimento de uma linha de pobreza em que se determina um dado nível de renda abaixo do qual os indivíduos são classificados como pobres. Da mesma forma, são rotulados como indigentes, miseráveis ou extremamente pobres aqueles cuja renda é insuficiente para satisfazer as necessidades alimentares, constituindo, assim, um subgrupo dos pobres.

Nesse aspecto, para subsidiar a análise da incidência da pobreza na América Latina este trabalho se apoia na metodologia adotada pela CEPAL, em que a linha de pobreza estabelecida leva em consideração o valor de uma cesta de bens e serviços, na moeda de cada país, que expresse o custo das necessidades básicas, considerando as necessidades nutricionais, os hábitos de consumo, a disponibilidade de alimentos e seus preços relativos, bem como as diferenças de preços existentes entre as áreas metropolitanas, urbanas e rurais. A linha de indigência corresponde à metade da linha de pobreza das áreas urbanas e a 1,75 das áreas rurais.

Os dados da CEPAL (2016) apontam para o fato de que tanto a pobreza quanto a indigência na região têm diminuído ao longo dos anos, embora os percentuais registrados permaneçam em patamares não satisfatórios. A pobreza em 2014 estava presente em $28,8 \%$ da população e a indigência em 11,8\%, o que correspondia a 168 milhões de latino-americanos em situação de pobreza e dentre esses 70 milhões em condições de indigência. 
A diminuição da incidência da pobreza e da indigência registrada no período - em 2002 a pobreza atingia $43,9 \%$ e a indigência 19,3\% - é resultante da recuperação do crescimento econômico, do incremento dos rendimentos do trabalho e da redução da desigualdade (CEPAL, 2016). Ressalta-se, porém, que embora haja uma tendência a redução do nível geral de pobreza ao longo dos anos, a região ainda apresenta muitos indivíduos e famílias em situação de vida precária, fato que contribuiu para a elaboração de medidas e políticas públicas sociais com vistas à reversão deste quadro.

A fim de caracterizar outros aspectos da pobreza na América Latina, deslocando-se um pouco dos critérios monetários, e para dar subsídios à apreciação dos programas de transferências condicionadas de renda presentes nesta região, serão aqui pautados alguns aspectos ligados às condições educacionais e de saúde.

É majoritariamente difundida a ideia de que os investimentos em educação e os níveis educacionais da sociedade têm relação direta não só com os rendimentos do trabalho apropriados individualmente, como também proporcionam retornos coletivos dados os ganhos de produtividade, o incremento das forças produtivas e o aumento da renda nacional. Tal argumentação geralmente é ilustrada pelos exemplos de alguns países centrais que dedicaram investimentos generosos em educação e que conquistaram bons níveis de crescimento e desenvolvimento econômico.

Rocha (2004) alega que a educação transcende a esfera econômica, pois além de ser matéria-prima fundamental para o aprimoramento da vida material e para o desenvolvimento econômico, é responsável pelas escolhas humanas diante da realidade, assumindo assim um papel relevante no desenvolvimento humano e ensejando a expansão da liberdade. Bruno (2011), a partir de uma inspiração marxiana, atenta para a não linearidade entre educação e desenvolvimento econômico, relacionando-a à reprodução da classe trabalhadora e evidenciando a dimensão política do capital.

Em se tratando da América Latina, carece-se repertoriar a existência de uma heterogeneidade educacional marcada por uma organização social altamente estratificada, reflexo da formação histórica, da concentração do poder e, via de regra, da falta de uma política educacional destinada a todos os segmentos populacionais, notadamente aos filhos e filhas das classes trabalhadoras.

O gasto público em educação reflete o quanto do Produto Interno Bruto (PIB) dos países é destinado à educação pública. A análise dos dados, conforme a CEPAL (2015), permite inferir que na região há pouco investimento na área - em 2010, Argentina, Chile, Colômbia, Equador, El Salvador, Guatemala, Guiana, Nicarágua, Paraguai e Peru não destinavam sequer 5\% do PIB para a educação - o que resulta na dificuldade do estabelecimento de um sistema educacional capaz de proporcionar uma adequada preparação de capital humano, dificultando o fomento/promoção do desenvolvimento.

Discutir educação é também discutir a situação daqueles que estão à margem do sistema educacional. $\mathrm{O}$ analfabetismo relaciona-se diretamente com a pobreza, uma vez que a sua incidência é maior nas regiões mais pobres (periféricas), prognosticando, desse modo, a desproteção social, a desigualdade e a precária qualificação profissional que dificultam o rompimento do círculo vicioso da pobreza ${ }^{1}$. Não se pode perder de vista que a educação é um dos ingredientes para o desenvolvimento, desconsiderando-se, porém, o automatismo.

A taxa de analfabetismo, que mostra a porcentagem da população acima de 15 anos de idade incapaz de ler e escrever, com entendimento (interpretar), um relato simples da sua vida cotidiana, decresceu em todos os países da região e na região como um todo. Contudo, os percentuais se mantêm altos denunciando a insuficiência de recursos que os países destinam à educação. Infere-se dessa situação que uma parcela significativa da população possui uma frágil compreensão sobre o seu entorno social, porque não é habilitada para tal, por não ter letramento. A porcentagem de analfabetos na América Latina, em linhas gerais, era de 14,9\% em 1990 e de 8,3\% em 2010 (CEPAL, 2015).

A saúde - que expressa qualidade de vida e é determinada por fatores econômicos, sociais, históricos e ambientais - pode ser utilizada para caracterizar o estabelecimento do bem-estar. Os investimentos em saúde são considerados como um pressuposto para o desenvolvimento e para o rompimento do ciclo intergeracional da pobreza. Investimentos, por exemplo, em estrutura hospitalar, em prontos-socorros, em educação em saúde, em atenção básica, em formação dos profissionais de saúde, em vacinação, em saneamento básico e em nutrição geram supostamente populações mais saudáveis, menos propensas a doenças e mais produtivas.

Viana e Elias (2007) ventilam que a melhoria das condições de saúde da população não é determinada exclusivamente pelas políticas de saúde, sendo também apurada pela política econômica e pelas políticas sociais, ou seja, pela combinação entre economia, democracia e bem-estar coletivo. Os autores entendem a relação entre saúde e desenvolvimento como um processo dinâmico que deve ligar crescimento econômico, mudanças na estrutura produtiva e melhoria do padrão de vida.

Observa-se que a incidência de doenças nas camadas menos abastadas da sociedade geralmente é superior à média registrada para a população como um todo, fato que explicita a vulnerabilidade desse grupo social. Os indivíduos acometidos pela pobreza têm na venda da sua força de trabalho a única fonte de renda. As doenças ao 
agravarem as suas condições físicas fazem com que alguns pobres, quando encontram trabalho, fiquem impossibilitados para o mesmo, aprofundando as suas carências e fazendo girar/perpetuar o ciclo da pobreza.

Na América Latina o percentual do PIB destinado aos gastos com a saúde pública, embora levemente mais expressivos do que os gastos educacionais, de acordo com a CEPAL (2016), também revelam a insuficiência de recursos direcionados para a área - nenhum país apurado apresenta gastos iguais ou superiores a $10 \%$ do PIB, tendo como referência o ano de 2014. A promoção do bem-estar físico e mental, em termos de gastos, não se configura como necessidades de primeira ordem, não em termos de provimento público.

Quando são selecionados distintos indicadores com a finalidade de caracterizar as condições de saúde dos países da região, conclui-se que a América Latina não apresenta, em linhas gerais, percentuais satisfatórios para nenhuma das taxas analisadas. Destaca-se o alto índice de mortalidade infantil $(22,5 \%)$ e de mortalidade de menores de cinco anos de idade (29,1\%), entre 2005-2010, o que denota a necessidade de proteção social, sem olvidar que a saúde também é um direito social. A única exceção nessa apreciação é a boa cobertura de crianças de 1 ano vacinadas contra o sarampo que está praticamente universalizada, $92 \%$ da população em 2013, segundo dados da CEPAL (2015).

É preciso registrar que dentre os países da América Latina, Cuba é o país que mais se destaca com dados positivos registrando os maiores investimentos, 12,8\% do PIB em educação, em 2013 e 10,6\% em saúde em 2009. Em decorrência disso, apresenta taxa de analfabetismo menor do que o da região como um todo, 2,1\%, em 2010, como também melhores indicadores de saúde. Peña e Proenza (2009) advogam que em Cuba a pobreza é caracterizada pelos baixos níveis de renda e pela precariedade habitacional, dada a oferta eficiente de serviços de educação e saúde.

\section{A experiência latino-americana com os programas de transferências condicionadas de renda}

Como já veiculado nesse texto, foi a partir da década de 1990 que as questões ligadas à desigualdade ganharam corpo e incitaram a formulação de políticas públicas direcionadas ao combate à pobreza. Nessa perspectiva, os Estados foram compelidos a desenhar políticas de proteção social mais específicas e direcionadas, uma vez que as políticas assim chamadas de universais, mas que na verdade eram extremamente meritocráticas de cunho bismarckiano, até então praticadas, não foram capazes de impedir a reprodução do quadro de iniquidade vivenciado pelos países da região latino-americana frente à dinâmica socioeconômica. Ivo (2003) esclarece que as políticas sociais focalizadas não se contrapõem as universais, elas apenas discriminam positivamente em favor dos grupos sociais que demandam mais cuidados.

Os programas de transferências condicionadas de renda podem ser definidos como auxílios monetários destinados a grupos sociais vulneráveis e de baixa renda acometidos pela pobreza ou miséria, amparados pela existência de contrapartidas (corresponsabilização) dos seus beneficiários. As condicionalidades para usufruto do benefício assentam-se em componentes voltados para a saúde, educação e nutrição, dada a relevância dessas dimensões para a superação das condições de pobreza e interrupção do ciclo intergeracional, bem como em um recorte de renda baseado em linhas de pobreza ou em índices específicos.

Cabe destacar que tais programas possuem um duplo objetivo: o alívio imediato da pobreza e o aumento do capital humano, sendo que existe a pretensão de possibilitar a emancipação das famílias. Para Villatoro (2010, p. 128), o cumprimento das pré-condições nas áreas da educação, saúde e nutrição diminuem os riscos futuros e potencializam o desenvolvimento das famílias para a superação da situação de vulnerabilidade, assim "[...] o sistema de proteção tem evoluído de uma perspectiva centrada na redução da pobreza no curto prazo, para um enfoque de administração de riscos, que tem como objetivo acrescentar o capital humano e superar a pobreza no longo prazo".

Draibe (2007) encara os programas de transferências condicionadas de renda da América Latina como resultantes de um processo evolutivo dos programas de combate à pobreza. Para essa autora estes programas possibilitaram a superação do entendimento da pobreza como, tão somente, insuficiência de renda (concepção neoliberal) e proporcionaram a compreensão de que se faz imperativa a integração entre diferentes setores, programas e políticas para transcender a pobreza, refutando, desse modo, a crença de que uma política sozinha seria capaz de equacioná-la.

É correto afirmar que os programas aludidos estão sintonizados com a lógica dos direitos sociais, uma vez que promovem e estimulam o acesso a estes, portanto não se restringem ao auxílio monetário, contemplam também ações que facilitam o acesso aos serviços sociais básicos e propõem a melhoria do consumo alimentar. Geralmente são muito centralizados no desenho e na estrutura, não havendo espaço para contribuições, no entanto são descentralizados na gestão pela necessidade de contato com as famílias e de físcalização sobre o cumprimento dos compromissos (DRAIBE, 2007). 
Outro aspecto que merece destaque é o papel desempenhado pelas condicionalidades. Estas são estipuladas dada a crença de que a educação e a saúde são condições fundamentais para a emancipação das famílias. Harmoniza-se com essa perspectiva o debate que Sen (2005) travou sobre a pobreza ao associá-la à obstrução dos funcionamentos e das capacidades imprescindíveis para tais. Sob sua lente a pobreza só pode ser superada - e o desenvolvimento alcançado - quando os indivíduos puderem fruir adequadamente dos recursos coletivos, tiverem seus direitos assegurados e puderem exercer a liberdade.

Draibe (2007), Nascimento e Reis (2009), Mattei (2010) e Villatoro (2010) elencam diferentes argumentos para expressar a relevância do cumprimento das condicionalidades pelas famílias para o usufruto do auxílio monetário. Eles defendem a ideia de que as contrapartidas ampliam o acesso dos indivíduos aos direitos sociais básicos e a outras políticas sociais fundamentais, estimulam o uso dos serviços públicos e impelem o poder público a ampliá-los, afastam a estigmatização daqueles que precisam receber o benefício e contribuem para uma melhor aceitação dos programas pelas sociedades.

De outro modo há de se reconhecer que se os direitos à educação e à saúde são universais não existe a necessidade de condicionamento das transferências de renda ao cumprimento de uma agenda de saúde e escolar. Se as políticas sociais focalizadas operam em sincronia com os direitos sociais elas não deveriam regular a transferência de renda a partir da garantia prévia de outros direitos. É o Estado que tem a obrigação de prover tais serviços à sociedade, cabe a ele a formulação de estratégias para a universalização de tais serviços, de fato e de direito.

Sob a ótica dos direitos, a um direito não se deve impor contrapartidas, exigências ou condicionalidades, uma vez que a condição de pessoa deve ser o requisito único para a titularidade de direitos. A responsabilidade em garantir o provimento e a qualidade desses serviços aos portadores desses direitos compete aos poderes públicos responsáveis. A obrigação do cumprimento das condicionalidades (garantir escolas, postos de saúde) nessa perspectiva, cabe a esses poderes, e não às pessoas. (ZIMMERMANN, 2006, p. 153).

O debate sobre o cumprimento das condicionalidades suscita algumas reflexões atinentes à emancipação das famílias dado o investimento intencional em capital humano. Será que o rigoroso comprometimento com os cuidados com a saúde e com a frequência escolar potencializam as famílias a superarem as condições de pobreza? As famílias ganharão autonomia e serão inseridas no mercado de trabalho após o desligamento dos programas? Há vagas suficientes para todos no mercado de trabalho?

Villatoro (2010) chama atenção para a não consideração da variável emprego na proposta de interrupção do círculo intergeracional da pobreza e afirma que as intervenções somente serão sustentáveis no longo prazo se forem capazes de modificar o comportamento das famílias em relação à educação e ao trabalho infantil.

Os programas de transferências condicionadas de renda são, em linhas gerais, financiados, apoiados e incentivados pelo Banco Mundial e pelo Banco Interamericano de Desenvolvimento - este último criado para mobilizar recursos financeiros com vistas à promoção do desenvolvimento regional, que contribuíram e contribuem, inclusive, com a formulação, monitoramento e avaliação dos referidos programas (MATTEI, 2010).

Não é ousada a afirmativa de que os programas de transferências condicionadas de renda são uma tendência geral no enfrentamento da pobreza na região. Lavinas (2014) os classifica como a grande novidade em termos de assistência social na primeira década de 2000. Villatoro (2010) alega que eles são componentes fundamentais da política antipobreza de muitos países latino-americanos e cooperam para o alcance das Metas do Milênio.

Apesar das peculiaridades, todos os programas implementados na região - com exceção do Equador (Bono de Desarrolo Humano) e da Venezuela (Bolsa Bolivariana) que não exigem condicionalidades recomendam cuidados com a saúde (cumprimento de calendário de vacinação, acompanhamento do desenvolvimento das crianças, gestantes e nutrizes, regularidade de consultas médicas, dentre outros) e frequência escolar mínima de crianças, adolescentes e jovens (MATTEI, 2010).

Constata-se também a existência de programas que preconizam cuidados alimentares, o desenvolvimento de atividades de inserção produtiva, a participação em cursos de geração de trabalho e renda, a frequência aos serviços de assistência social, a participação em seminários educativos com temas transversais ligados à saúde, educação, planejamento familiar, higiene, alimentação e violência.

Os programas desenhados e em curso na América Latina estão aquém de abranger todas as famílias e indivíduos acometidos pela pobreza. Avaliando o critério de abrangência destacam-se o Brasil (Bolsa Família) e o México (Oportunidades), talvez por terem sido os pioneiros da região na formulação e na implementação dessas políticas. De acordo com Draibe (2007), os programas de transferências condicionadas de renda são dinâmicos e ao longo do tempo vão se ajustando positivamente na concepção, no desenho, na operacionalização, no monitoramento e na articulação com outras políticas. 
É legítimo repertoriar que os valores repassados para as famílias variam de acordo com o orçamento dos países, mas geralmente são baixos, levando-se em conta a capacidade de compra de uma cesta de bens e serviços e o atendimento das necessidades sociais básicas. $\mathrm{O}$ auxílio monetário ou é concedido mensalmente, regressivo ou não, ou em uma só parcela. A transferência de renda assume um caráter complementar para as famílias pobres.

Salienta-se ainda que a liberdade na aplicação do recurso auferido é uma entre as vantagens apontadas pelas famílias beneficiárias. O benefício proporciona o atendimento das necessidades alimentares e o alívio imediato da fome. Entretanto, não é aconselhável se distanciar da noção de que as políticas focalizadas constituem apenas um meio temporário para que as famílias alcancem os direitos sociais básicos que são universais.

Para Mattei (2010, p. 8) os programas possuem natureza diversa e atuam "[...] ou como amortecedores dos efeitos negativos produzidos pelas crises econômicas, ou como instrumento alternativo às ações das redes tradicionais de proteção social que enfrentam dificuldades nas esferas econômica e política para atingir seus objetivos".

Nascimento e Reis (2009) alegam que apesar da pulverização dos programas de transferência de renda na América Latina, estes são ineficazes para o combate à pobreza e a alteração do quadro de desigualdade. Na mesma linha de raciocínio, Villatoro (2010, p. 139) ratifica que esses programas "logram, em alguns casos, reduzir a brecha da pobreza que afeta as famílias pobres, e em outros, mitigar as consequências de uma crise econômica. No entanto, não está clara a sua potência para lograr que os beneficiários superem a linha de pobreza".

Reconhece-se, contudo, que as avaliações dos programas de transferências de renda mostram recorrentemente o impacto positivo destes na redução da fome e da pobreza e tal eficácia estimula o prosseguimento e a reprodução desse tipo de política social na região. Nesse sentido são escamoteadas, muitas vezes, as discussões relativas à universalização dos direitos, talvez pela crença de que o cumprimento das condicionalidades seja capaz de por fim ao ciclo intergeracional da pobreza.

Não se pode desconsiderar o contexto de forte concentração de renda e de intensas desigualdades sociais, assinalado por um grande contingente populacional em situação de pobreza e miséria, como ilustram alguns dados socio-

\section{[...] as transferências}

condicionadas de renda latinoamericanas cumprem o seu papel de promover um lenitivo às más condições de vida, no entanto, ao não se registrar, em linhas gerais, a conjugação com outras políticas mais amplas e efetivas, capazes de darem respostas às múltiplas faces e dimensões da pobreza, tolhe-se a capacidade que os programas teriam para estimular o ultraje da pobreza. econômicos da região, apresentados neste texto. Neste sentido, as transferências monetárias, que foram planejadas como um meio não só de aliviar, como também, aliadas às corresponsabilidades, de instrumentalizar as famílias pobres a ultrajarem a pobreza, a se emanciparem desta condição no longo prazo. Ao que tudo indica há a necessidade da conjugação desses programas com outras políticas universais.

É inegável a ressonância salutar que os programas de transferências condicionadas de renda possuem entre as parcelas sociais contempladas e/ou que demandam os benefícios, fato que elucida sobre o nível de despossesão e pobreza em que vivem, mesmo se forem considerados os baixos valores monetários repassados. São evidentes as respostas assertivas que eles dão no sentido de mitigar a fome no curto prazo. No entanto, tais programas ainda estão longe de estimularem/promoverem o ultraje da pobreza - seja pelos módicos valores repassados, seja pela falta de cobertura total da população que necessita, pela fragilidade na oferta de serviços públicos atinentes às áreas das condicionalidades, pelos baixos investimentos sociais ou pela não concomitância de políticas estruturantes e redistributivas que seriam capazes de alterar o quadro de concentração que engendra desigualdades de diferentes matizes na região.

\section{Considerações finais}

A pobreza na América Latina passou a ser alvo prioritário das políticas públicas com o recrudescimento da iniquidade e das desigualdades provocadas, sobretudo, pelo prosseguimento do ideário neoliberal. Reconheceu-se tardiamente que a pobreza obstruía a consecução do desenvolvimento da região. Frente a esse reco- 
nhecimento brotou a precisão de formular políticas específicas e bem direcionadas àqueles em situação precárias, daí emergiram os programas de transferências condicionadas de renda.

A pulverização de tais programas na América Latina, enquanto política social focalizada para o equacionamento dos altos índices de pobreza, trouxe consigo a proposta de investimento na acumulação do capital humano, especialmente de crianças e jovens, com a intenção de romper o ciclo vicioso da pobreza, atacar suas causas e superá-la nas gerações futuras. As corresponsabilidades para usufruto do benefício concentram-se prioritariamente nas áreas da educação e da saúde e suscitam discussões atinentes aos direitos sociais. Considerando-as como ferramentas imprescindíveis não só para o rompimento do ciclo da pobreza, mas também como pilares de sustentação do desenvolvimento, como apregoam os programas, é contraditório constatar que todos os países da região (com exceção de Cuba) investem tão pouco nestas pastas.

Por outro lado, reconhece-se que o cumprimento das condicionalidades, por si só, é incapaz de emancipar as famílias e promover a superação das condições de pobreza, uma vez que não se percebe uma articulação consolidada entre estes programas e a política de empregos, por exemplo. Uma família de baixa renda, com boa formação educacional e ótima condição de saúde também pode ser assaltada pela pobreza.

As transferências de renda oriundas desses programas, conforme a CEPAL (2016), contribuem em um menor grau para a redução da pobreza do que os rendimentos provenientes do trabalho. Com base nessa informação, infere-se que, na prática, as transferências monetárias assumem papel secundário no enfrentamento da pobreza na região, sendo capazes apenas de abrandá-la, em que pese à popularidade dos programas e a relevância conferida ao benefício pelas famílias contempladas. Torna-se imperativo o delineamento de outras medidas que sejam capazes de afrontar a alta incidência da pobreza nos países latino-americanos.

Ademais, a proeminência das transferências monetárias na América Latina relega ao segundo plano as discussões atinentes ao caráter estrutural da pobreza na região e ao repartimento da riqueza socialmente produzida, refletindo um caráter de controle/manutenção do status quo, frente à mitigação da fome e pobreza proporcionada por essas políticas. Não se pode perder de vista que a fome e a pobreza estão também relacionadas ao processo de acumulação selvagem existente na região, agravadas pelo prosseguimento das políticas neoliberais.

Por fim, as transferências condicionadas de renda latino-americanas cumprem o seu papel de promover um lenitivo às más condições de vida, no entanto, ao não se registrar, em linhas gerais, a conjugação com outras políticas mais amplas e efetivas, capazes de darem respostas às múltiplas faces e dimensões da pobreza, tolhese a capacidade que os programas teriam para estimular o ultraje da pobreza. Em que pese o debate sobre as más condições de vida, risco e vulnerabilidade social que tais programas suscitam na região, sem esquecer que foi essa contenda que os gestou, a ausência de ações efetivas que promovam a redistribuição e alteração do quadro de pobreza estrutural da região faz com que também se ventile a ideia de que tais programas são um meio de ajustamento às condições de pobreza.

\section{Referências}

BALANCO, P. A. F.; PINTO, E. C. Crise e capitalismo contemporâneo: a questão das saídas “internas" e "externas". In: WANDERLEY, L. A.; SEPÚlVEDA, O. G. (Org.). Reflexões de Economistas Baianos (2007-2008). Salvador: CORECON/BA, 2008. p. 77-103.

BARROS, R. P. de; CARVALHO, M. de; FRANCO, S. Pobreza Mutidimensional no Brasil. Rio de Janeiro: IPEA, 2006. (Texto para discussão n. 1227).

BRESSER-PEREIRA, L. C. As três interpretações da dependência. Perspectivas, São Paulo, v. 38, p. 17-48, jul./dez. 2010. Disponível em: $<$ http://www.bresserpereira.org.br/papers/2009/09.11.Tres_interpretacoes_dependencia.Perspectivas_26.pdf $>$.Acesso em: 15 fev. 2017.

BRUNO, L. Educação e desenvolvimento econômico no Brasil. Revista Brasileira de Educação, Rio de Janeiro, v. 16, n. 48, p. 545-562, set./dez. 2011. Disponível em: <http://www.scielo.br/pdf/rbedu/v16n48/v16n48a02.pdf>. Acesso em: 15 fev. 2017.

CHESNAIS, F. (Coord.). A mundialização financeira: gênese, custos e riscos. São Paulo: Xamã, 1998.

COMISIÓN ECONÓMICA PARA AMÉRICA LATINA Y EL CARIBE. Panorama Social de América Latina 2015. Santiago: CEPAL, 2016.

Anuario Estadístico de América Latina y el Caribe 2015. Santiago: CEPAL, 2015.

COSTA LIMA, M. Desenvolvimento e globalização na periferia: o elo perdido. In: ARAÚJO, C.; AMADEO, J. (Org.). Teoria Política Latino Americana. São Paulo: Hucitec, 2009. v. 1, p. 77-102.

COUTO, J. M. O pensamento desenvolvimentista de Raúl Prebisch. Economia e Sociedade, Campinas, v. 16, n. 1, p. $45-64$, abr. 2007. Disponível em: <http://www.eco.unicamp.br/docprod/downarq.php?id=628\&tp=a>. Acesso em: 15 fev. 2017.

DRAIBE, S. Programa Oportunidades (México) Programa Puente/Chile Solidário (Chile). Campinas, SP: Núcleo de Estudos de Políticas Públicas/UNICAMP, jun. 2007. 
ESPÍNOLA, G. M.; ZIMMERMANN, C. R. Definição e Mensuração da Pobreza: algumas considerações sobre o debate recente. In: CONGRESSO INTERNACIONAL INTERDISCIPLINAR EM CIÊNCIAS SOCIAIS E HUMANIDADES, 1., 2012, Niterói. Anais... Niterói: ANINTER-SH/PPGSD-UFF, 2012. Disponível em: <http://www.aninter.com.br/ANAIS\%20I\%20CONITER/ GT01\%20Movimentos\%20sociais\%20e\%20desigualdades/>. Acesso em: 15 fev. 2017.

IGLESIAS, E. V. O papel do Estado e os paradigmas econômicos na América Latina. Revista CEPAL. Santiago, n. esp. em port., p. 4553, maio 2010. Disponível em: <http://repositorio.cepal.org/bitstream/handle/11362/11390/NEP045053.pdf;jsessionid= 1953E06A4458BC35E316F9B0E26163E2?sequence=1>. Acesso em: 15 fev. 2017.

IVO, A. B. L. Políticas Sociais de Combate à Pobreza nos anos 90: novas teses, novos paradigmas. In: SUPERINTENDÊNCIA DE ESTUDOS ECONÔMICOS E SOCIAIS DA BAHIA. Pobreza e Desigualdades Sociais. Salvador: SEI, 2003. p. 7-27. (Série Estudos e Pesquisas, 63).

KAGEYAMA, A.; HOFFMANN, R. Pobreza no Brasil: uma perspectiva multidimensional. Revista Economia e Sociedade, Campinas, SP, v. 15, n. 1 (26), p. 79-112, jan./jun. 2006. Disponível em: <http://www.eco.unicamp.br/docprod/downarq.php?id=603\&tp=a>. Acesso em: 15 fev. 2017

LAVINAS, L. La Asistencia Social en el siglo XXI. New Left Review, v. 84, p. 7-48, jan./fev. 2014. Disponível em: <http://newleftreview.es/ article/download_pdf?language=es\&id=3041>. Acesso em: 15 fev. 2017.

MATTEI, L. Notas sobre programas de transferência de renda na América Latina. Florianópolis: IELA/UFSC, 2010. (Texto para discussão, n. 10).

MENDONÇA, E. L. de. Reflexões críticas sobre a pobreza e sua mensuração no Brasil dos anos 1990. In: SUPERINTENDÊNCIA DE ESTUDOS ECONOMICOS E SOCIAIS DA BAHIA. Pobreza e Desigualdades Sociais. Salvador: SEI, 2003. p. 75-83. (Série Estudos e Pesquisas, 63).

NASCIMENTO, A. F. do; REIS, C. N. dos. Os programas de transferência condicionada de renda na América Latina: especificidades de uma realidade que se mantém. Revista de Políticas Públicas, São Luís, v. 13, n. 2, p. 183-193, jul./dez. 2009. Disponível em: <http:// meriva.pucrs.br:8080/dspace/bitstream/10923/7932/2/OS_PROGRAMAS_DE_TRANSFERENCIA_ CONDICIONADA_DE_RENDA_NA_AMERICA_LATINA_especificidades_de_uma_realidade_que_se_mantem.pdf $>$. Acesso em: 15 fev. 2017

PEÑA, A.; PROENZA, D. Capital social y pobreza urbana: el lugar de las instituciones oficiales en la superación de la precariedad en territorios periféricos de Ciudad de La Habana, Cuba. Revista de Estudos e Pesquisas sobre as Américas, Brasília, DF, v. 3, n. 2, p. 19, jul./dez. 2009. Disponível em: <http://periodicos.unb.br/index.php/repam/article/view/1357/1012>. Acesso em: 15 fev. 2017.

ROCHA, F. J. M. Educação e economia: uma abordagem sobre as consequências e condicionantes econômicos do desenvolvimento humano, com ênfase em educação. Caderno de Finanças Públicas, Brasília, DF, n. 5, p. 51-171, jul. 2004. Disponível em: <http:// www.esaf.fazenda.gov.br/assuntos/biblioteca/arquivos-gerais/arquivo.2014-05-21.1236224325>. Acesso em: 15 fev. 2017.

ROCHA, S. Pobreza no Brasil: afinal, de que se trata? Rio de Janeiro: FGV, 2005.

SEN, A. Desenvolvimento como liberdade. São Paulo: Cia. das Letras, 2005.

SILVA, M. O. da S e. O. Bolsa Família: problematizando questões centrais na política de transferência de renda no Brasil. Ciência \& Saúde Coletiva, Rio de Janeiro, v. 12, n. 6, p. 1429-1439, nov./dez. 2007. Disponível em: <http://www.scielo.br/pdf/csc/v12n6/ v12n6a04.pdf>. Acesso em: 15 fev. 2017.

VIANA, A. L. D.; ELIAS, P. E. M. Saúde e Desenvolvimento. Ciência \& Saúde Coletiva, Rio de Janeiro, v. 12, suppl., p. 1765-1777, nov. 2007. Disponível em: <http://www.scielo.br/pdf/csc/v12s0/02.pdf>. Acesso em: 15 fev. 2017.

VILLATORO, P. Programas de transferências monetárias condicionadas: experiências na América Latina. Revista CEPAL, Santiago, n. esp. em port., p. 127-141, maio 2010. Disponível em: <https://www.cepal.org/publicaciones/xml/0/39540/RVPVillatoro.pdf $>$. Acesso em: 15 fev. 2017.

ZIMMERMANN, C. R. Os programas sociais sob a ótica dos direitos humanos: o caso do Bolsa Família do Governo Lula no Brasil. Sur. Revista Internacional de Direitos Humanos, São Paulo, v. 3, n. 4, p. 145-159, jun. 2006. Disponível em: <http://www.scielo.br/ scielo.php?script=sci_arttext\&pid=S1806-64452006000100009>. Acesso em: 15 fev. 2017.

\section{Nota}

1 Em conformidade com a literatura econômica, entende-se como círculo vicioso da pobreza ou ciclo intergeracional da pobreza as condições econômicas, políticas e sociais que obstruem a superação das causas da pobreza, fazendo com que ela seja retroalimentada e reproduzida pelas gerações subsequentes.

\section{Gepherson Macêdo Espínola}

gepherson@hotmail.com

Mestrado em Gestão de Políticas Públicas e Segurança Social pela Universidade Federal do Recôncavo da Bahia (UFRB) 
Professor do Curso de Especialização em Educação, Pobreza e Desigualdade Social da Universidade Federal da Bahia (UFBA)

\section{UFBA}

Faculdade de Educação

Av. Reitor Miguel Calmon, s/n, sala EPDS - Canela

Salvador - Bahia - Brasil

CEP: $40.110-100$

\section{Clóvis Roberto Zimmermann}

clovis.zimmermann@gmail.com

Doutorado em Sociologia pela Universidade Heidelberg, Alemanha

Professor Adjunto de Sociologia da Universidade Federal da Bahia (UFBA)

\section{UFBA}

Faculdade de Filosofia e Ciências Humanas

Estrada de São Lázaro, 197 - Federação

Salvador - Bahia - Brasil

CEP: $40.210-730$ 